\title{
Teachers' Perceptions Towards Web-Based School Information System (SIS) in Developing Parents-Teacher Relationship
}

\author{
Malasari, Sri Lestari, Lina Kumalasari, Farid Ahmadi \\ Graduate School Program, Universitas Negeri Semarang, Indonesia \\ malasari.lala@gmail.com
}

\begin{abstract}
The study examined teachers' response towards web-based School Information System (SIS) in enhancing parents-teacher relationship. The development and implementation of technology in a state of education field was examined as were the benefits realized by implementing web-based SIS. As school increasingly embrace the relationship of its stakeholders, web-based SIS will become stronger and pervasive. Viewing teachers, students, and parents as customers provides a competitive advantage for the school to enhance school's ability to cooperate as well as serve its customers. Questionnaires were conducted to 11 teachers who have been used web-based SIS for at least a year. Some participants were then additionally interviewed to get their deep thoughts. The benefits of implementing web-based SIS in specifically primary school setting include improve teachers' administration works, parents' access towards their children's education, school's credibility image, and satisfaction with the school's services. This technology has been implemented limited to some private schools only. Using technology to assist the success of a school will become a more pervasive act in the future since viewing the teachers, students, and parents as the honoured stakeholders will attract school's ability in serving their customers.
\end{abstract}

Keyword: Web-Based, Relationship, SIS

\section{Introduction}

Technology has been widely used in every aspect in life specifically in education field. Technology is not only used by the teachers in the classroom to deliver learning materials, but it is also used by the administrator to take care of school's administration. Therefore, schools started to invest the information communication technology (ICT) in the form of hardware, software, networking, and staff development to improve the school performance effectiveness (Condie, et al., 2007). In line with that, the use of information communication technology in education field has been rapidly increased these days. This can be seen through the number of providers arising to fulfill the school's needs. Information technology in education management has described as a well-designed functional operation (Tantall, et al., 2001).

Furthermore, the occurrence of web-based School Information System (SIS) is one of examples of the intertwining between information technology in education management and school's context. A School Information System is a management system for education purposes. SIS provided accesses to students' assessment scores, tracking students' attendance, online reports, and other student-related data needed in a school. The features included in an SIS for each school may vary in accordance to their needs. SIS is used by schools to support a range of administrative activities (Shah, 2013).

Furthermore, in Indonesian schools, webbased SIS has been used from primary level to higher education level. In primary level, most schools that use the web-based SIS are private schools. It is happened because those schools are supported by some providers that need extra money to spend. One of providers that has been widely used is Quintal. It has been serving more than 15 schools all around Indonesia. The SIS product they offer is a holistic modern academic portal that can be used by the administrators, teachers, students, and parents. The SIS products they serve are in the form both web-based and phone application-based. The web-based SIS was used by the school while phone applicationbased SIS was used by the parents. It showed that smartphone can facilitate teachers-parents communication (Ho, et al., 2013). A study also stated that teachers regularly communicate with the families of the students, yet few are prepared for this professional activity (Walker \& Legg, 2018). In other words, web-based SIS is one of best choice to provide a medium for this professional activity. 
One of the main objectives from the SIS is to make administration works efficient and effective. Most concern of the decision in using SIS is to make a bridge of communication to the parents in a very effective way since the most important element of parental involvement in education is communication (Hill, et al., 2016). Moreover, parent-teacher communication is evolving due to smartphones and other communication technologies (Thompson, et al., 2015). In Indonesia context, parents are attentive to their child's progress. Some studies have found that parental involvement improved both students' achievement and behavior (Sirvani, 2007; Thijs \& Eilbracht, 2012). In the context of school, students and parents are customers that the stronger bond they can make, the higher the satisfaction and the loyalty got from the customers. The use of web-based SIS was not the first way of communication in this technology era, there was a study in which Media Richness Theory was applied between parents and teachers when they communicated in the starter of smartphone era (Thompson \& Mazer, 2012). It is believed that parental involvement showed commitment from the parents to the students' development (Pomerantz, et al., 2007).

Reflecting on the previous elaboration, this study aims at exploring teachers' perception towards the implementation of web-based school information system in developing parents-teachers relationship. Therefore, this paper reaffirms the benefit of SIS as one of communication ways to develop cooperation between school and parents. This paper also aims to find out some problems from the teacher when implementing webbased SIS in their daily work. This would be beneficial to create a suitable choice that suits the millennial era.

\section{Methods}

This study employed a qualitative design through a case study since it investigated a phenomenon. In relation to this study, the phenomena investigated was how the webbased School Information System (SIS) could develop teachers-parents' relationship and the problems that arise in the implementation has been done in research to obtain results in line with the objectives. Eleven teachers from primary level were selected purposively to participate in the study. Thus, five teachers were willing to do the interview to support their answers to questionnaires. Moreover, documentations were taken as a supporting data to this study. In analyzing the data, the questionnaires were segmented and summarized to find out the patterns of information gained. Furthermore, the interview then was transcribed and coded to find out the participants' perceptions towards the implementation of web-based SIS in developing teacher-parent' relationship.

\section{Results and Discussion}

\subsection{Teachers' perceptions towards web- based SIS}

Based on the data, it is found that the school in which this study took place carries out SIS in the form of web for the management and teachers while parents use mobile application SIS. The features included in the web-based SIS used by the participants includes students' scores record, attendance, assignments or homework information, school events, class test schedule, learning materials, communication with students and parents, and polling/survey.

All participants in this study has been using web-based SIS for about 18 months. The findings point of teachers' perception on webbased SIS showed a good response towards developing teachers-parents' relationship. It is revealed from the questionnaires data that 11 out of 11 participants agreed that web-based SIS could accommodate the communication between the teachers and parents as shown below.

P4: By using Quintal, parents can check their child's attendance and scores as well as assignments given by the teachers at school. Parents can ask questions to the teachers directly online.

P8: Through the Quintal, parents are able to know the attendance, class test scores, assignments, and events at school.

Furthermore, it is strengthened by the interview data as shown below.

P1: It gives additional medium to communicate with the parents aside from the formal letter being sent. It also opens a door for easy and free communication for the inquiries, 
complains, and suggestions of the parents.

P3: Parents as the guidance at home can communicate and follow up their child's progress with the homeroom teacher. Therefore, parents' and teachers' roles are actively intertwined.

P6: It gives information about school events, students' scores, test schedule to the parents. It even can be a reminder for parents who activate the application's notification on their smartphone.

It is in line with the study conducted in Malaysian schools that the use of SIS gave better accessibility to information and more efficient administration (Zain \& Atan, 2004). It is also known that since the turn of $21^{\text {st }}$ century, computer mediated communication has changed the nature of parent-teacher way of communication (Thompson, 2008). In relevant to this study, SIS brought a number of benefits to a large number of stakeholders that are administration, teachers, students, and parents (Samaha \& Shishakly, 2008). Therefore, when parental involvement increased, they are making a positive impact to a successful educational system (Durisic \& Bunijevac, 2017) and students' achievement (Chen, et al., 2007). In addition, web-based SIS is offered as an effective way to build relationship to the parents which can be accessed anytime and anywhere.

\subsection{Challenges faced during implementation of SIS}

The second theme is related to the problems encountered by the teachers and answering the second research question. Based on the findings, it is found that there were three main problems faced by the teachers in implementing the web-based SIS. There was internet connectivity, difficulties in contacting the server when problems occurred, and some parents' refusal to use the web-based SIS.

Firstly, internet connectivity became the main problem in implementing the web-based SIS since it needed to be online and the information were served in actual time. Bad internet connectivity might bring the webbased SIS into different result. Other than making teachers' work more efficient by doing it paperless, bad internet connectivity gave a turnover result. It was because when it happened, the teachers could not work at all.
They needed to wait until the connection became better and was ready to use. By doing so, teachers felt they were wasting their time. In line with this, the result from the interview with some participants showed the same thing as seen below.

P3: Sometimes it is very difficult to access the Quintal. I think it happens when too many teachers attempt to access the web but the connectivity is not strong enough to cover all the demands.

P6: Availability and internet connection speed. Since web-based SIS is dependent on it, it is difficult to finish one's work if these problems arise.

Aside from the connection problems, some teachers also found it stressful when they needed to change basic information such as full name of students or marking scheme of the subject they taught. It happened because in the site of this study, the web-based SIS was provided by a provider in which basic information was filled by them and it was only them who got accessed to change the information and the scores counting policy. Some participants revealed it on an openended question in the questionnaires given that can be seen below.

P9: I teach English Lesson for Primary 3. The computation of the marking scheme is too complicated. I used to work with my excel so even though I use this web-based SIS to record the students' scores, I still have it in my Excel's files. When I wanted to synchronize the final score, I was surprised that both results were so far different. Then, yes, I called the server person to confirm the computation they put in the web. My feeling was right. They put it wrongly. Then, I needed to wait for four days to get it correct. So wasting my time!

The last concern from the participants towards the implementation of web-based SIS was some refusals of the parents to use the web-based SIS. Although teachers' perception towards the implementation of web-based SIS was positive, some participants still found few parents who insisted on using common communication way they used. This finding is in line with the interview result as below. 
P6: Oh yeah, it is not that easy to make parents use this application. Some of them are fixed with their mind that asking teachers in person is much easier and efficient. However, if we think more of it, if they use the SIS, the information is in their hands hahahaha.

However, the participants believed that everything from web-based SIS was useful for teachers. Computation of grades, inputting the attendance of the students, informing tests, homework, and events are some of the aspects that help teachers upgrade their skills and knowledge for them to be stagnant on what they had learned and for them to cope with the competitive world. Moreover, through this web-based SIS, teachers could build communication with the parents regarding students' progress at school. Parents' role in this were expected to increase students' achievement (Mapp \& Kuttner, 2013). Moreover, parents-teacher relationship would also build trust between parents as customers and the school itself (Adams \& Christenson, 2000; Stone, 2003).

In the present study, a web-based SIS is an efficient way to share information of the students to their parents. It was revealed that the information shared were regarding to the scores, class test schedule, attendance, school events, and learning materials. This study also showed that parents found it easy to access their children's achievement at school since the web-based SIS can be accessed from the touch of their hand. Not only the parents, but teachers also found it helpful to their time management. Teachers did not need to be bothered by the parents who always seek for students' test scores. In addition, there were some obstacles found it the implementation of web-based SIS such as the quality of broadband connectivity, the difficulties in contacting the server when problems arise and socialization to all parents to use the webbased SIS.

\section{Conclusion}

Reflecting on the previous elaboration of findings, the implementation of web-based SIS showed positive attitude from all teachers as the participants in this study. Furthermore, based on the findings of the present study, it is suggested that web-based SIS needs to be applied in schools. Thus, there should be some development and maintenance to solve some problems. Moreover, the school needs to socialize more on the application of both webbased and phone application-based of SIS so that all parents can get the benefits from it

\section{References}

Adams, K. S. \& Christenson, S. L. (2000). Trust and the family-school relationship: Examination of parent-teacher differences in elementary and secondary grades. Journal of School Psychology, 38, 477497.

Chen, H., Yu, C., \& Chang, C. (2007). Ehomebook system: A web-based interactive education interface. Computers and Education, 49, 160-175, doi:10.1016/j.compedu.2005.05.003.

Condie, R., Munro, B., Seagraves, L., \& Kenesson, S. (2007). The impact of ICT in schools - a landscape review. Coventry: Becta. Available at: http://webarchive.nationalarchives.gov.uk/2 0101102103654/publications.becta.org.uk/d ownload.cfm?resID=28221.

Durisic, M. \& Bunijevac, M. (2017). Parental Involvement as an Important Factor for Successful Education. C-E-P-S Journal, 7(3). Retrieved from https://files.eric.ed.gov/fulltext/EJ1156936. pdf.

Hill, N. E., Witherspoon, D. P., \& Bartz, D. (2016). Parental involvement in education during middle school: Perspectives of ethnically diverse parents, teachers, and students. The Journal of Educational Research, doi: 10.1080/00220671.2016.1190910.

Ho, L., Hung, C., \& Chen, H. (2013). Using theoretical models to examine the acceptance behavior of mobile phone messaging to enhance parent-teacher interactions. Computers \& Education, 61, 105-114, doi:10.1016/j.compedu.2012.09.009.

Mapp, K. L. \& Kuttner, P. J. (2013). Partners in Education: A dual capacity-building framework for family-school partnerships. Retrieved 
http://www.sedl.org/pubs/framework/FECap-Building.pdf.

Pomerantz, E. M., Moorman, E. A., \& Litwack, S. D. (2007). The how, whom, and why of parents' involvement in children's academic lives: More is not always better. Review of Educational Research, 77, 373-410.

Samaha, A. M. A. \& Shishakly, R. (2008). Assessment of School Information System Utilization in the UAE Primary Schools. Issues in Informing Science and Information Technology, 5 (1). Retrieved from:

https://pdfs.semanticscholar.org/9fe6/fe234 15e0e41fca022a96f4df190f48b7c0f.pdf.

Shah, M. (2013). Impact of management information systems (MIS) on school administration: What the literature says. Social and Behavioral Sciences, 116(2014), 2799 - 2804. Retrieved from: https://www.hamyarprojeh.ir/wpcontent/uploads/2016/10/Www.TarjomehF a.IR-Englisi-3758.pdf.

Sirvani, H. (2007). The Effect of Teacher Communication with Parents on Students' Mathematics Achievement. American Secondary Education, 36(1), 31-46.

Stone, S. (2003). The Transition to High School: Teacher and Parent Perspectives in a Large, Urban, Predominantly Minority School System. Journal of Ethnic and Cultural Diversity in Social Work, 12, 4767.

Tantall, A. \& Davey, B. (2001). Open ITEM systems are good ITEM systems. Proceedings of the IFIP TC $3 / W G 3.7$ Fourth International Working Conference on Information Technology in Educational Management: Pathways to Institutional Improvement with Information Technology in Educational Management, Deventer the Netherlands, pp 59-70.

Thijs, J. \& Eilbracht, L. (2012). Teachers' Perceptions of Parent-Teacher Alliance and Student-Teacher Relational Conflict: Examining the Role of Ethnic Differences and 'Disruptive' Behavior. Psychology in the Schools, 49 (8): 794-808.

Thompson, B. (2008). Characteristics of parent-teacher e-mail communication. Communication Education, 57, 201-223, doi:10.1080/0363452070.

Thompson, B. \& Mazer, J. P. (2012). Development of the parental academic support scale: Frequency, importance, and modes of communication. Communication Education, 61, 131-160, doi:10.1080/03634523.2012.657207.

Thompshon, B., Mazer, J. P., \& Grady, E. F. (2015). The Changing Nature of ParentTeacher Communication: Mode Selection in the Smartphone Era. Communication Education, 64(2), 187-207, doi: 10.1080/03634523.2015.1014382.

Walker, J. M. T. \& Legg, A. M. (2018). Parent-Teacher Conference Communication: A Guide to Integrating Family Engagement Through Simulated Conversations about Student Academic Progress. Journal of Education for Teaching, doi: 10.1080/02607476.2018.1465661.

Zain, M. Z. M. \& Atan, H. Y. I. (2004). The impact of information and communication technology (ICT) on the management practices of Malaysian Smart Schools. International Journal of Educational Development, 24, 201-211. 